Yıl: 2021, Cilt: 54, Sayı: 3, 701-720

DOI: 10.30964/auebfd.755654, E-ISSN: 2458-8342, P-ISSN: 1301-3718

\title{
Beden Eğitimi Öğretmenlerinin Eğitimde Mizah Kullanımına Yönelik Tutumları
}

\begin{tabular}{lccc}
\hline MAKALE TÜRÜ & Başvuru Tarihi & Kabul Tarihi & Yayım Tarihi \\
Araştırma Makalesi & 20.06 .2020 & 26.07 .2021 & 03.09 .2021 \\
\hline
\end{tabular}

Bijen Filiz

Afyon Kocatepe Üniversitesi

Yasin Karaca iD ${ }^{2}$

Osmaniye Korkutata Universitesi

\begin{abstract}
Öz
Mizah, en karmaşık, en yoğun ders ortamlarında bile araştırmayı, bilgi sahibi olmayı ve yaratıcılığı kolaylaştıran özelliklere sahiptir. Mizah bu özellikleriyle eğitimi canlı tutar. $\mathrm{Bu}$ araştırmada, Beden Eğitimi öğretmenlerinin eğitimde mizah kullanımına yönelik tutumlarının belirlenmesi ve cinsiyet, medeni durum, yaş ve mesleki hizmet yılı değişkenlerine göre incelenmesi amaçlanmıştır. Araştırmada genel tarama modeli kullanılmıştır. Araştırma grubunu kolay örnekleme yöntemine göre seçilen 140 gönüllü Beden Eğitimi öğretmeni oluşturmuştur. Araştırmada Eğitimde Mizahın Kullanımına Yönelik Tutum Ölçeği kullanılmıştır. Araştırmanın veri analizinde, betimsel istatistik için frekans ve yüzde, ortalama ve standart sapma analizi; ilişkisiz ölçümlerde toplam puanların karşılaştırılması için Varyans analizi (Tek Yönlü ANOVA, bağımsız örneklem t testi), anlamlı farklılığın hangi gruplar arasında olduğunu belirlemek için Tukey testi kullanılmıştır. Araştırma sonucunda, cinsiyete göre Beden Eğitimi ögretmenlerinin eğitimde mizah kullanmaya yönelik tutumlarında anlamlı bir fark bulunmamıştır. Evli Beden Eğitimi öğretmenlerinin mizahı eğitimde gerekli görme tutumlarının daha fazla olduğu; mesleğe yeni başlayan Beden Eğitimi öğretmenlerinin mizahı eğitimde gerekli görme ve dil ve öğretime etki inançlarının daha fazla olduğu, yaşı daha fazla olan Beden Eğitimi öğretmenlerinin sınıf düzeninin sağlanmasına etkide mizahı kullanma tutumlarının daha fazla olduğu belirlenmiştir. Araştırmanın en önemli sonucu, eğitimin etkililiği açısından, Beden Eğitimi öğretmenlerinin eğitimde mizah kullanımına yönelik tutumlarının yüksek düzeyde olmasıdır.
\end{abstract}

Anahtar sözcükler: Beden eğitimi öğretmeni, eğitim, mizah, eğitimde mizah, tutum.

Etik kurul kararı: Bu araştırma, Afyon Kocatepe Üniversitesi Sosyal ve Beşeri Bilimleri Bilimsel Araştırma ve Yayın Etiği Kurulu'nun 27.05.2020 tarih ve 04 toplantı sayılı izni ile uygun bulunmuştur.

${ }^{1}$ Sorumlu Yazar: Doç. Dr., Spor Bilimleri Fakültesi, Antrenörlük Eğitimi Bölümü, E-posta: bijenfiliz@gmail.com, https://orcid.org/0000-0001-5863-3861

${ }^{2}$ Dr. Öğr. Üyesi, Kadirli Uygulamalı Bilimler Yüksekokulu, Rekreasyon Yönetimi Bölümü, E-posta: yasinkaraca99@gmail.com, https://orcid.org/0000-0001-6024-7679 
Mizah, insanoğlunun karşısına bazen güldüren, bazen düşündüren, bazen de yaşamın gülümseten yüzü olarak ortaya çıkmaktadır. Tarihten günümüze yaşamın her alanında yer alan mizah, son yıllarda çeşitli etmenlerle birlikte araştırılmaya başlanmıştır. Bu doğrultuda eğitim-mizah ilişkileri ve öğretmenlerin eğitimde mizah kullanma tarzlarıyla ilgili ulusal ve uluslararası düzeyde çeşitli araştırmalar yapılmıştır. Yapılan araştırmalarda mizah-eğitim ilişkilerini etkileyen etmenlere değinilmiş, öğretmenlerin eğitimde mizahı kullanma tarzları çeşitli değişkenlere göre incelenmiştir. Beden Eğitimi öğretmenlerinin eğitim ortamlarında mizahı kullanım tarzlarıyla ilgili neredeyse hiç araştırma yapılmadığ 1 gözlenmiştir. Bu bağlamda araştırmanın konusu, Beden Eğitimi öğretmenlerinin mizahı kullanımına yönelik tutumları olmuştur.

Mizah olaylara esprili bir bakışla yaklaşan, insana neşe ve mutluluk veren bir olgudur. İnsan yaşamının doğal bir parçası olan mizah, insanı güldürerek beden ve ruh dengesinin korumasına yardımcı olabilir. İnsanlar yaşamları boyunca çeşitli sorunlar ve zorluklarla karşı karşıya kalabilirler. İnsan günlük yaşamında mizaha yer vermezse karşılaştı̆̆ Mizahın sağladığı yumuşatıcı atmosfer bu tür durumların üstesinden gelinmesine veya daha kolay atlatılmasına yardımcı olur. Mizah insanın anlama yeteneğini (kabiliyetini) ve yaratıcılığını geliştirerek dünyaya ve olaylara farklı bir açıdan bakabilmesini sağlar. Anlatılması güç bir konu veya verilmesi zor bir ileti mizah sayesinde kolayca aktarılabilir. Bu açıdan mizah, birey ve toplum yaşamında önemli bir yere sahiptir.

Mizah, içerik olarak çözümlenmesi kolay olmayan, belirli bir sınır çizilemeyen kavramdır. İnsan yaşamında yer alan bu kavram, çoğu zaman önemsenmemiş olsa da, daha sonraları araştırılan konular arasında yer almıştır. Mizahla ilgili yaklaşık 500 tanım, kavram, düşünce bulunmaktadır (Berk, 2003). Dolayısıyla mizah tanımlanırken ve değerlendirilirken fikralar, şakalar, komik yorumları içeren sayısız öğe göz önünde bulundurulur (Ruch, 1998). Bu yüzden araştırmacılar mizahın tanımı ve nasıl değerlendirileceği konusunda uzlaşı sağlayamamışlardır. Lovorn ve Holaway (2015) mizahı komik olmanın ve insanları güldürmenin bir yolu olarak tanımlamıştır. Başka bir tanımda mizah, kişiye komik gelen bir durum veya ifade sonucu, gülümseme veya gülmeyle sonuçlanan ve genellikle kişiyi hoşnut eden bir durumdur (Susa, 2002).

Mizah, politikadan sosyal olaylara, alışkanlıklardan, güncel konulara kadar günlük yaşamın her aşamasında yer almaktadır. Kırıcı ve hırpalayıcı olmamak kaydiyla her olay mizah konusu olabilir (Pala, 1995). Mizah, herhangi bir sorun karşısında sorunun çözümüne ve uzlaşı ortamının oluşmasına katkı sunar (Mierop, 1999; Yardımcı, 2010). Mizah kişilerin birbiriyle kaynaşmasını kolaylaştırarak kişiler arası etkileşimi arttırır (Provine, 1996). Mizah acıyı azaltma ve kalp ile kasları güçlendirmeye olan katkılarından dolayı bir tür fiziksel ve psikolojik rahatlama aracıdır (Dupré, 1998). Mizah kullanımı sonucu gülen bir kişi kendisini mutlu ve rahatlamış hisseder. Mizah stresi azaltarak sinirleri yatıştırmaya ve kişinin 
sakinleşmesine yardımcı olur. Mizahın bilinen yararlarının yanı sıra mizahı bütün boyutlarıyla değerlendirmek zordur (Yardımcı, 2010). Çünkü mizah bazen olumlu bazen de olumsuz duygular sonucunda ortaya çıkabilmektedir. Araştırmacılar bir kişinin kendini üstün göstermek amacıyla karşısındaki kişiyle alay etmesini, olumsuz duygulardan kaynaklanan bir davranış olarak değerlendirirken bireyin dinlediği bir fikra sonucu gülmesini ise olumlu duygulardan kaynaklanan bir davranış olarak değerlendirmektedirler. Hangi tür duygu durumu söz konusu olursa olsun gerçekleşen gülme eyleminin bireyi psikolojik olarak rahatlattığı düşünülmektedir (Çelik, 2014). $\mathrm{Bu}$ açıdan ele alındığında birçok disiplin mizahı uygulanabilir bir eğitimbilimsel (pedagojik) yaklaşım olarak görmekte ve kullanmaktadır. Özellikle eğitim ortamında öğrenci-öğretmen ilişkisi ve öğrencilerin bu ilişkiye yönelik memnuniyet düzeyini öngörmede ve güçlü bir ilişki kurmada mizah kullanımı önemli rol oynamaktadır.

Bu tanımlar ve değerlendirmeler mizah hakkında bir düşünce rtaya koymaktadır. Burada ön plana çıkarılması gereken mizahın eğitimle olan ilişkisidir. Eğitim ortamında mizahın insanları sadece güldürmek için kullanılmadığını ele alan bir anlayışla konunun değerlendirilmesi gerekir (Polimeni ve Reiss, 2006). Çünkü mizahın öğrencileri güldürmenin yanında gerginlik ve stresi azaltan, öğrenciöğretmen ilişkisini geliştiren, öğrencilerin öğrenmesini kolaylaştıran bir yapısı vardır (Lei, Cohen ve Russler, 2010). Mizah kişiler arası iletişimi kolaylaştırarak sıcak bir ortamın oluşmasını sağlar ve öğrencilere farklı bir hissiyat verir. Bu nedenle mizah eğitimin bir parçası olmalıdır (Jeder, 2015).

Mizahın eğitimde kullanılması konusunda öğretmenlerin önemli rol oynadığı görülmektedir. Mizah çoğu sosyal etkileşim biçimlerinde olağandır ve varsayımları kabul görülmektedir. Mizah duygusu öğretmenlerde bulunması gereken temel niteliklerinden birisi olarak görülmektedir. Öğretmenler çoğu zaman derslerde ortamı rahatlatmak ve hafifletmek için şakalar, komik benzeşimler, imalar, ironiler, rol yapma vb. kullanarak mizah oluştururlar. Öğretmen mizahı kullanarak öğrenci üzerinde güven, rahatlama, gevşeme, yaşama olumlu bakış ve iyi olma gibi niteliklerin oluşmasına yardımcı olur. Öğretmenler derslerde mizah kullanmanın yeni yollarını keşfetmeli, şakadan anlamalı, olayların gülünç taraflarını öngörebilmeli, öğrencileri incitebilecek söz ve davranışlardan kaçınmalıdır (Yılmaz, 2010). Öğretmenler mizahı doğru yerde kullandığı zaman öğretmek istediği konuya öğrencinin dikkatini çekmeyi başarır. Öğrenci doğru kullanılan mizah sayesinde çıkarımları ayırt edebilir, olumlu deneyimler yaşar ve derse olan güdülenmesi artar. $\mathrm{Bu}$ durum öğrencinin akademik başarısını da arttırabilir (Jeder, 2015).

Eğitimde mizahın kullanımıyla ilgili yapılan araştırmalarda (Alatalo ve Poutiainen, 2016; Garner, 2006; Halula, 2013; Minchew ve Hopper, 2008; Vu ve Lan, 2012) daha çok sınıf ortamında mizah uygulamalarına odaklanıldığı görülmektedir. Ayrıca bu araştırmalar sınıf ortamlarında mizah kullanımının öğrenmeye olumlu yönde katkı sağladığını ortaya koymuştur. Araştırmacıların en çok üzerinde durduğu konulardan birisi mizahın sınıf ortamında kullanılma yönteminin nasıl olması gerektiğidir. Bazı araştırmacılar mizahla ilgili baskın yaklaşımı belirli mizahların 
uygunluğuna yanıt olarak değerlendirirken bazı araştırmacılar sınıf ortamında kullanılan mizahın öğrencinin dikkatinin dağılmasına yol açarak öğretmenin anlattığı konuya odaklanmasını zorlaştırdığını ileri sürmüşlerdir. Ancak tüm araştırmacılar doğru yerde kullanılmadığında ve içeriğine dikkat edilmediğinde mizahın rahatsız edici olabildiğini belirtmektedirler (Davis, 2015).

Alanyazında öğretmenlerin mizah algılarına yönelik yapılan araştırmalara bakıldığında, Kember ve Kwan (2002) öğretmenlerin sınıfta mizahı kullanmalarını salık vermektedir. Torok, McMorris ve Lin (2004) tarafindan sınıf ortamında kullanılan mizahın öğretmeyi ve öğrenmeyi kolaylaştırdığı görülmüştür. Garner (2006) özellikle istatistik gibi yoğun ilgi gerektiren derslerde kullanılan mizahın öğrencilerin öğrenmelerine büyük katkı sağladığını belirtmiştir. Ziyaeemehr, Kumar ve Abdullah (2011), öğretmenin mizahı etkin kullanmasının küçük eğitimbilimsel (pedagojik) araştırmaların nasıl yapıldığını tanımlamada önemli olduğunu vurgulamıştır. Ayrıca mizahı sınıfta etkin bir şekilde kullanmayan öğretmenlerin bu konuda eğitim almadığı için mizahı kullanmadığı sonucuna ulaşmışlardır. Diğer yandan Harland (2012), eğitimde öğretmenin iyi bir mizah anlayışına sahip olmasını onun en etkili özelliklerinden birisi olduğunu belirtmiştir. Yılmaz (2014) derslerde mizahı etkili ve verimli kullanan öğretmenlerin vazgeçilmez öğretmen olduğunu dile getirmektedir. Tait, Lampert, Bahr ve Bennett (2015,) mizahı eğitici bir eğlence olarak değerlendirerek mizahın eğitim ve eğlencenin birleşimi olarak ele alınması gerektiğini belirtmişlerdir. Yine aynı araştırmada, mizahı eğitimde kullanmayı tercih eden öğretmenlerin öğretim tekniklerini şekillendirmede oldukça başarılı oldukları görülmüştür. Altınkurt ve Yılmaz (2016) da okul ikliminin mizahı destekleyici nitelikte olmasının, öğretmenlerin mizah algılarını ve derslerde mizah kullanımını olumlu yönde etkileyeceğini belirtmişlerdir. Araştırma sonuçları mizahın doğru ve etkin kullanımı konusunda öğretmenlerin önemli rol oynadığını ve öğretme- öğrenme sürecinde etkili olduğunu göstermektedir.

Eğitimde mizahın kullanımı Beden Eğitimi öğretmeni bağlamında ele alındığında, Beden Eğitimi öğretmeni için mizah, öğrencilerin derse olan ilgilerini sürekli kılmak, dersi sevdirmek ve eğlenceli duruma getirmek, öğrenmeyi kolaylaştırmak için kullanılması gereken etkili bir araçtır. Beden Eğitimi öğretmeni derste mizahı kullanarak dersin doğası gereği yetenek ve cesaret gerektiren sportif hareketler karşısında öğrencilerin streslerini ve heyecanlarını azaltmaya, onları cesaretlendirmeye yardımcı olabilir. Ayrıca Beden Eğitimi öğretmeni oyun içerikli derslerde mizahı kullanarak öğrencilerden ve oyun tarzından kaynaklanan zorlu, heyecanlı ve gergin durumlar karşısında ortamı yumuşatabilir. Bu açıdan Beden Eğitimi öğretmenlerinin eğitim ortamlarında daha etkili bir öğrenme gerçekleştirebilmek için derslerinde mizah kullanmayı tercih etmelerinin yararlı olacağı düşünülmektedir. Nitekim Yüksek Öğretim Kurulu (YÖK) öğretmenlik meslek ölçütlerinde, beden eğitimi ve spor dersini vermek için gerekli koşulları taşıyan bir öğretmenin mizah, oyun ve yaratıcı dramayı bir arada kullanabilme yeteneğine sahip olması gerektiği belirtilmektedir (YÖK, 2007). Bu nedenle beden eğitimi ve spor dersindeki kazanımları gerçekleştirmede, öğretmenin kullandığı 
öğretim yöntemlerini daha etkili hale getirme, öğrencileri derse güdüleme, derse karşı sevgi ve ilgilerini arttırma açısından eğitimde mizahın kullanımına yönelik Beden Eğitimi öğretmenlerinin tutumlarının araştırılmasında yarar vardır. Dersin eğlenceli duruma getirilmesi en önemli motivasyon kaynaklarından biridir. Eğlenceli duruma getirilen bir ders, eğitimin her aşamasında motive edici bir etki oluşturur (Yılmaz, 2010). Ayrıca mesleğini en iyi şekilde yapan öğretmenler başarılı olmanın yollarını ararlar. Bu bilgiler ışığında Beden Eğitimi öğretmenlerinin meslek hayatlarında daha başarılı olabilmesi için eğitimde mizahın kullanımına yönelik tutumlarının araştırmaya değer bir konu olduğu düşünülmektedir. Böylece Beden Eğitimi öğretmenlerinin mizah tarzları üzerinde etkili olan etmenleri ve sorunları ortaya çıkarmak ve bu sorunlara çözüm yolları bulmak olanaklı olabilecektir.

\section{Araştırmanın Amacı}

$\mathrm{Bu}$ araştırmada, Beden Eğitimi öğretmenlerinin eğitimde mizah kullanımına yönelik tutum düzeylerinin belirlenmesi; ayrıca cinsiyete, medeni duruma, yaşa ve mesleki hizmet yılına göre anlamlı bir farklılık olup olmadığının tespit edilmesidir.

\section{Yöntem}

Araştırmanın bu bölümünde araştırmanın modeli, çalışma grubu, veri toplama aracı ve veri analizine ilişkin bilgilere yer verilmiştir.

\section{Araştırma Modeli}

Araştırmada nicel araştırma desenlerinden genel tarama modeli kullanılmıştır. Tarama modeli, geçmişte ya da şimdi var olan bir durumu var olduğu şekilde betimlemeyi amaçlayan bir araştırma türüdür (Karasar, 2018).

\section{Çalışma Grubu}

Araştırma grubunu, 2019-2020 eğitim-öğretim yılında Afyon'da görev yapan, dahil edilme ölçütlerini karşılayan (Beden Eğitimi öğretmeni olan) ve araştırmaya ilgi duyduklarını belirten öğretmenlerin katıldığı bir kolay örnekleme tekniğine göre seçilen 140 Beden Eğitimi öğretmeni oluşturmuştur. Araştırmaya katılan öğretmenlerin 74'ü (\%52.9) erkek ve 66'sı (\%47.1) kadındır. Medeni duruma göre 74 'ü (\%52.9) evli ve 66'sı (\%47.1) bekardır. Öğretmenlerin 39'u (\%27.9) 23-29 yaş, 68'i (\%48.6) 30-39 yaş, 33’ü (\%23.5) 40-49 yaşındadır. Öğretmenlerin 74'ü (\%52.9) 1-5 yıldır, 21 'i (\%15.0) 6-10 yıldır, 20'si (\%14.3) 11-15 yıldır, 25'i (\%17.8) 16 ve üstü yıldır öğretmen olarak görev yapmaktadır.

Araştırma öncesinde Afyon Kocatepe Üniversitesi Sosyal ve Beşeri Bilimleri Bilimsel Araştırma ve Yayın Etiği Kurulundan gerekli izin alınmıştır (15.06.2020- E. 17011). Afyon ilinde görev yapan Beden Eğitimi öğretmenleriyle iletişime geçilmiştir ve veriler Google anket üzerinden elektronik ölçek ile toplanmıştır. Elektronik ölçeğin ön bilgilerinde, katılımcıların araştırmaya katıldığını kabul eden bir onay ifadesi, çalışmanın amacı, ölçeği doldurma süresi, çalışmaya dahil edilme ölçütleri ve katılımcıların cayma hakları yer almıştır. Ön bilgileri kabul eden öğretmenler ölçeği doldurmuşlardır. 


\section{Veri Toplama Araçları}

Araştırmada Eğitimde Mizahın Kullanımına Yönelik Tutum Ölçeği kullanılmıştır.

Eğitimde mizahın kullanımına yönelik tutum ölçeği. Ölçek, Balta (2016) tarafindan geliştirilmiştir. Geliştirilen ölçek, farklı branşlardaki toplam 313 öğretmene uygulanmıştır. Ölçek, beşli Likert tipli yapıdadır, 17 maddeden ve üç alt boyuttan $(\alpha$ $=.92$ ) oluşmaktadır. Birinci alt boyut eğitimde gerekli görme (5 madde, $\alpha=.85$ ), ikinci alt boyut dil ve öğretime etki ( 8 madde, $\alpha=.88$ ) ve üçüncü alt boyut ise sinıf düzenine olan etki ( 4 madde, $\alpha=.75$ ) olarak tanımlanmıştır. Birinci alt boyut için "Mizah olaylara farklı açıdan bakabilmeyi sağlar.", ikinci alt boyut için "Mizahın öğreticilik yönü vardır.", üçüncü alt boyut için "Mizah sınıfta kurulu olan düzeni bozar." maddeleri örnek olarak verilebilir. Ölçeğin sınıf düzenine olan etki alt boyutuna ait olan dört madde ters puanlanmaktadır. Ölçekten alınabilecek minimum puan 17 , maksimum puan ise $85^{\prime}$ tir. Puanların düşmesi olumsuz tutum düzeyini, yükselmesi olumlu tutum düzeyini belirtmektedir.

$\mathrm{Bu}$ çalışma için yapılan güvenirlik analizi sonucunda, ölçeğin Cronbach Alfa değerleri, üç alt boyut için .92, eğitimde gerekli görme alt boyutu için .85 , dil ve ögretime etki alt boyutu için .88 , sınıf düzenine olan etki alt boyutu için .75 olarak bulunmuştur.

\section{Verilerin Analizi}

Verilerin analizinde; betimsel istatistik için frekans ve yüzde analizi; öğretmenlerin eğitimde mizah kullanımına yönelik tutum düzeylerini belirlemek için ortalama ve standart sapma analizi; toplam puanların karşılaştırılmasında cinsiyet ve medeni durum değişkenleri için bağımsız örneklem $t$ testi, yaş ve mesleki hizmet yılı değişkenleri için Tek Yönlü ANOVA analizi; hangi gruplar arasında anlamlı fark olduğunu belirlemek amacıyla Tukey testi kullanılmıştır. Analizlerde SPSS 23.0 İstatistik Programından yararlanılmıştır.

Çalışmada parametrik testleri kullanmadan önce sütun (histogram) ve dağılım grafikleri incelendiğinde, eğrinin simetrik bir dağılım gösterdiği ve Çarpıklık ile basıklık değerlerinin -1.5 ile +1.5 arasinda olduğu görülmüştür (Tabachnick ve Fidell, 2013). Ayrıca Tek Yönlü ANOVA ve t testi analizleri için örneklemin homojenliği cinsiyet, medeni durum, yaş ve hizmet yllına göre Levene testi ile incelenmiş, $\mathrm{p}$ değerinin .05 'ten yüksek olduğu saptanmış ve grup varyanslarının eşit olduğu görülmüştür. Değişkenlere göre ölçeğin normallik ve Levene testi değerleri Tablo 1'de verilmiştir. 
Tablo 1

Beden Eğitimi Öğretmenlerinin Eğitimde Mizahın Kullanımına Yönelik Tutum Ölçeğinden Aldıkları Puanların Çarpıklık ve Basıklık Katsayıları, Levene Testi (F) Sonuçları

\begin{tabular}{|c|c|c|c|c|c|c|c|}
\hline \multirow[b]{2}{*}{ Değişken } & & \multirow[b]{2}{*}{$\mathbf{n}$} & \multicolumn{2}{|c|}{ Çarpıklık Katsayısı } & \multicolumn{2}{|c|}{ Basıklık Katsayısı } & \multirow[b]{2}{*}{$\mathbf{F}$} \\
\hline & & & $\begin{array}{r}\text { Katsayı } \\
\text { değeri }\end{array}$ & $\begin{array}{r}\text { Standart } \\
\text { hata }\end{array}$ & $\begin{array}{r}\text { Katsayı } \\
\text { değeri }\end{array}$ & $\begin{array}{r}\text { Standart } \\
\text { hata }\end{array}$ & \\
\hline \multirow{2}{*}{ Cinsiyet } & Erkek & 74 & -.586 & .279 & .413 & .552 & $p=.906$ \\
\hline & Kadın & 66 & -.550 & .295 & -.464 & .582 & $\mathrm{~F}=.016$ \\
\hline \multirow{2}{*}{$\begin{array}{l}\text { Medeni } \\
\text { durum }\end{array}$} & Evli & 74 & -.429 & .279 & .030 & .552 & $\mathrm{p}=.353$ \\
\hline & Bekar & 66 & -.595 & .295 & -.199 & .582 & $\mathrm{~F}=.869$ \\
\hline \multirow{3}{*}{ Yaş } & $23-29$ & 39 & -1.069 & .378 & .557 & .741 & $\mathrm{p}=.395$ \\
\hline & $30-39$ & 68 & -.246 & .291 & -.821 & .574 & $\mathrm{~F}=.935$ \\
\hline & $40-49$ & 33 & -.177 & .409 & -.209 & .798 & \\
\hline \multirow{4}{*}{$\begin{array}{l}\text { Mesleki } \\
\text { hizmet } \\
\text { y1lı }\end{array}$} & $1-5$ & 74 & -.918 & .279 & .676 & .552 & $\mathrm{p}=.778$ \\
\hline & $6-10$ & 21 & -.520 & .521 & -.196 & .972 & $F=.365$ \\
\hline & $11-15$ & 20 & -.317 & .512 & 1.081 & .992 & \\
\hline & 16 ve üstü & 25 & .720 & .205 & -1.091 & .407 & \\
\hline
\end{tabular}

Tablo 1'deki sonuçlara göre veri setinin parametrik testler için uygun olduğuna karar verilmiştir.

\section{Bulgular}

Araştırmanın bu bölümünde Beden Eğitimi öğretmenlerinin eğitimde mizahı kullanımlarına yönelik tutum düzeyleri ve bu tutumlarının cinsiyet, medeni durum, yaş ve mesleki hizmet yılına ilişkin bulgularına yer verilmiştir. Araştırmada Beden Eğitimi öğretmenlerinin eğitimde mizah kullanımına yönelik tutum düzeylerini belirlemede ortalama ve standart sapma analizinden yararlanılmıştır. Sonuçlar Tablo 2'de sunulmuştur.

Tablo 2

Beden Ĕ̆itimi Öğretmenlerinin Eğitimde Mizah Kullanımına Yönelik Tutum Düzeyleri

\begin{tabular}{lcccrr}
\hline Alt Boyutlar & $\mathbf{n}$ & $\overline{\boldsymbol{X}}$ & $\mathbf{S}$ & $\begin{array}{r}\text { En küçük } \\
\text { değer }\end{array}$ & $\begin{array}{r}\text { En büyük } \\
\text { değer }\end{array}$ \\
\hline Eğitimde gerekli görme & 140 & 4.57 & .49 & 3.00 & 5.00 \\
Dil ve öğretime etki & 140 & 4.38 & .61 & 2.25 & 5.00 \\
Sinıf düzeninin sağlanmasına etki & 140 & 2.14 & .78 & 1.00 & 5.00 \\
\hline
\end{tabular}

Tablo 2 incelendiğinde, Beden Eğitimi öğretmenlerinin eğitimde mizah kullanımına yönelik tutumlarının eğitimde gerekli görme alt boyutunda çok yüksek $(4.57 \pm .49)$, dil ve öğretime etki alt boyutunda çok yüksek $(4.38 \pm .61)$ ve sinıfta düzen sağlanmasına etki alt boyutunda düşük $(2.14 \pm .78)$ düzeyde olduğu 
görülmektedir. Araştırmada Beden Eğitimi öğretmenlerinin cinsiyete göre eğitimde mizah kullanımına yönelik tutumları $t$ testi ile analiz edilmiştir. Sonuçlar Tablo 3 'te sunulmuştur.

Tablo 3

Beden Ĕ̆itimi Öğretmenlerinin Cinsiyete Göre Eğitimde Mizah Kullanımına Yönelik Tutumları

\begin{tabular}{llrrrrr}
\hline Alt Boyutlar & Cinsiyet & $\mathbf{N}$ & $\overline{\boldsymbol{X}}$ & $\mathbf{S s}$ & $\mathbf{t}$ & $\mathbf{P}$ \\
\hline Eğitimde gerekli görme & Erkek & 74 & 22.71 & 2.64 & .72 & .472 \\
& Kadın & 66 & 23.01 & 2.17 & & \\
\hline Dil ve öğretime etki & Erkek & 74 & 34.31 & 5.29 & 1.89 & .060 \\
& Kadın & 66 & 35.86 & 4.27 & & \\
\hline Sınıf düzeninin sağlanmasına etki & Erkek & 74 & 8.22 & 3.29 & 1.34 & .183 \\
& Kadın & 66 & 8.93 & 2.92 & & \\
\hline
\end{tabular}

Tablo 3 incelendiğinde, Beden Eğitimi öğretmenlerinin eğitimde mizah kullanımına yönelik tutumlarında cinsiyete göre anlamlı bir farklılık bulunmamıştır $(p>.05)$. Araştırmada Beden Eğitimi öğretmenlerinin medeni duruma göre eğitimde mizah kullanımına yönelik tutumları $\mathrm{t}$ testi ile analiz edilmiştir. Sonuçlar Tablo 4'te sunulmuştur.

Tablo 4

Beden Ĕ̆itimi Öğretmenlerinin Medeni Duruma Göre Eğitimde Mizah Kullanımına Yönelik Tutumları

\begin{tabular}{llrrrrrr}
\hline Alt Boyutlar & $\begin{array}{l}\text { Medeni } \\
\text { durum }\end{array}$ & $\mathbf{n}$ & $\overline{\boldsymbol{X}}$ & Ss & $\mathbf{t}$ & $\mathbf{p}$ & $\mathbf{n}^{2}$ \\
\hline Eğitimde gerekli görme & Evli & 74 & 24.31 & 2.04 & 2.38 & .023 & .039 \\
& Bekâr & 66 & 22.34 & 2.73 & & & - \\
\hline Dil ve öğretime etki & Evli & 74 & 35.56 & 5.04 & 1.35 & .187 & - \\
& Bekâr & 66 & 34.45 & 4.66 & & & \\
\hline Sinıf düzeninin sağlanmasına etki & Evli & 74 & 8.63 & 3.23 & .28 & .781 & - \\
& Bekâr & 66 & 8.48 & 3.04 & & & \\
\hline
\end{tabular}

Tablo 4 incelendiğinde, Beden Eğitimi öğretmenlerinin eğitimde mizah kullanımına yönelik tutumlarının medeni duruma göre eğitimde gerekli görme ( $t=$ 2.38; $p$.05) alt boyutunda anlamlı bir farklılık bulunmuştur. Eğitimde gerekli görme alt boyutunda etki büyüklüğü Cohen'e (1988) göre orta etki düzeyinde hesaplanmıştır $\left(\mathrm{n}^{2}=.039\right)$. Evli olan Beden Eğitimi öğretmenlerinin olmayanlara göre eğitimde mizahı gerekli görme inancınının daha fazla olduğu görülmektedir. Araştırmada Beden Eğitimi öğretmenlerinin yaşa göre eğitimde mizah kullanımına yönelik tutumları Tek Yönlü ANOVA ile analiz edilmiştir. Sonuçlar Tablo 5'te gösterilmektedir. 
Tablo 5

Beden Ĕ̆itimi Öğretmenlerinin Yaşa Göre Ĕ̆itimde Mizah Kullanımına Yönelik Tutumlart

\begin{tabular}{lrrrrrrrrr}
\hline Değişkenler & Yaş & $\mathbf{n}$ & $\overline{\boldsymbol{X}}$ & $\mathbf{S s}$ & $\mathbf{d}$ & $\mathbf{F}$ & $\mathbf{p}$ & $\mathbf{n}^{\mathbf{2}}$ & Tukey \\
\hline Sınıf düzeninin & $23-29$ & 39 & 7.48 & 2.54 & 2 & 3.90 & .002 & .099 & $23-29$ \\
sağlanmasina etki & $30-39$ & 68 & 8.75 & 3.26 & 137 & & & & $<40-49$ \\
& $40-49$ & 33 & 9.45 & 3.23 & 139 & & & & \\
\hline
\end{tabular}

Tablo 5 incelendiğinde, Beden Eğitimi öğretmenlerinin eğitimde mizah kullanımına yönelik tutumlarının yaşa göre sınıf düzeninin sağlanmasına etki $\left(F_{(2,137)}\right.$ $=3.90, p<.05)$ alt boyutunda anlamlı bir farklılık bulunmuştur. Eğitimde gerekli görme $\left(F_{(2,137)}=1.42, p>.05\right)$ ve dil ve öğretime etki $\left(F_{(2,137)}=1.76, p>.05\right)$ alt boyutlarında anlamlı bir farklılık bulunmamıștır. Sınıf düzeninin sağlanmasına etki alt boyutunda etki büyüklüğü Cohen'e (1988) göre büyük etki düzeyinde hesaplanmıştır $\left(\mathrm{n}^{2}=.099\right)$. Çoklu karşılaştırma test (Tukey) sonucuna göre, 40-49 yaş aralığındaki Beden Eğitimi Öğretmenleri 23-29 yaş aralığındaki öğretmenlere göre eğitimde mizahın sınıf düzeninin sağlanmasına etkisinin daha fazla olduğu inancındadır. Araştırmada Beden Eğitimi öğretmenlerinin mesleki hizmet yılına göre eğitimde mizah kullanımına yönelik tutumları Tek Yönlü ANOVA ile analiz edilmiştir. Sonuçlar Tablo 6'da gösterilmektedir.

Tablo 6

Beden Ĕ̆itimi Öğretmenlerinin Mesleki Hizmet Yllına Göre Ĕ̆itimde Mizah Kullanımına Yönelik Tutumları

\begin{tabular}{|c|c|c|c|c|c|c|c|c|c|}
\hline Değişken & Hizmet yılı & $\mathbf{N}$ & $\overline{\boldsymbol{X}}$ & Ss & d & $\mathbf{F}$ & $\mathbf{p}$ & $n^{2}$ & Tukey \\
\hline \multirow{4}{*}{$\begin{array}{l}\text { Eğitimde } \\
\text { gerekli } \\
\text { görme }\end{array}$} & 1. $1-5$ & 74 & 23.02 & 2.42 & & \multirow[t]{4}{*}{3.85} & \multirow[t]{4}{*}{.011} & \multirow[t]{4}{*}{.096} & $1>3$ \\
\hline & 2. $6-10$ & 21 & 23.90 & 1.75 & 3 & & & & \multirow[t]{3}{*}{$2>3$} \\
\hline & 3. $11-15$ & 20 & 21.50 & 2.46 & 136 & & & & \\
\hline & 4. 16 ve üstü & 25 & 22.56 & 2.51 & 139 & & & & \\
\hline \multirow{4}{*}{$\begin{array}{l}\text { Dil } \\
\text { öğretime } \\
\text { etki }\end{array}$} & 1. $1-5$ & 74 & 35.78 & 4.37 & & \multirow[t]{4}{*}{3.05} & \multirow[t]{4}{*}{.031} & .063 & \multirow[t]{4}{*}{$1>3$} \\
\hline & 2. $6-10$ & 21 & 36.00 & 4.21 & 3 & & & & \\
\hline & 3. $11-15$ & 20 & 32.55 & 5.40 & 136 & & & & \\
\hline & 4. 16 ve üstü & 25 & 34.04 & 5.76 & 139 & & & & \\
\hline
\end{tabular}

Tablo 6 incelendiğinde, Beden Eğitimi öğretmenlerinin eğitimde mizah kullanımına yönelik tutumlarının mesleki hizmet yılına göre eğitimde gerekli görme $\left(F_{(3,136)}=3.85, p<.05\right)$ ve dil ve öğretime etki $\left(F_{(3,136)}=3.05, p<.05\right)$ alt boyutlarında anlamlı bir farklılık belirlenmiştir. Sınıf düzeninin sağlanmasına etki $\left(F_{(3,136)}=.40, p\right.$ $>$.05) alt boyutunda anlamlı bir farklılık bulunmamıştır Gruplar arasında etki büyüklüğü, eğitimde gerekli görme alt boyutunda Cohen'e (1988) göre büyük etki düzeyinde $\left(\mathrm{n}^{2}=.096\right)$, dil ve öğretime etki alt boyutunda orta etki düzeyinde $\left(\mathrm{n}^{2}=\right.$ .063) hesaplanmıştır. Çoklu karşılaştırma test (Tukey) sonucuna göre, 1-5 ve 6-10 
hizmet yılı olan Beden Eğitimi öğretmenlerinin 11-15 hizmet yılı olanlara göre eğitimde mizahı daha fazla gerekli görme inancında oldukları; 1-5 hizmet yılı olan öğretmenlerin 11-15 hizmet yılı olanlara göre eğitimde mizahın dil ve öğretime etkisinin daha fazla olduğu inancında olduğu görülmektedir.

\section{Tartışma, Sonuç ve Öneriler}

$\mathrm{Bu}$ araştırmada Beden Eğitimi öğretmenlerinin eğitimde mizah kullanımına yönelik tutumları belirlenmiş ve eğitimde mizah kullanımına yönelik tutumları cinsiyet, medeni durum, yaş ve mesleki hizmet yılı değişkenlerine göre incelenmiştir. Mizah, eğitim ortamında etkili bir araçtır. Dolayısıyla öğretmenlerin eğitimde mizaha yönelik tutumları ve hazırbulunuşlukları önemli görülmektedir (Oral, 2004). Bu bağlamda eğitimin etkililiği açısından, Beden Eğitimi öğretmenlerinin eğitimde mizah kullanımına yönelik tutumlarının yüksek düzeyde olması önemli bir sonuçtur.

Araştırmada Beden Eğitimi öğretmenlerinin eğitimde mizah kullanımına yönelik tutumlarının eğitimde gerekli görme ve dil ve öğretime etki alt boyutlarında çok yüksek, sınıfta düzen sağlanmasına etki alt boyutunda düşük düzeyde olduğu belirlenmiştir. Dolayısıyla Beden Eğitimi öğretmenlerinin eğitimde mizah kullanımını gerekli görme inançlarının ve dil ve öğretime etkisi açısından mizahı kullanmaya yönelik inançlarının oldukça yüksek olduğu fakat sınıf disiplinini sağlama açısından eğitimde mizah kullanmaya yönelik inançlarının düşük düzeyde olduğu görülmektedir. Yapılan bazı çalışmalarda öğretmenlerin mizaha yönelik tutumlarının olumlu yönde olduğu belirlenmiştir (Balta, 2016; Chaniotakis, 2012; Omede ve Daku, 2013).

Araştırmada cinsiyete göre Beden Eğitimi öğretmenlerinin eğitimde mizah kullanımına yönelik tutumlarında anlamlı bir farklılık saptanamamıştır. Sepetçi (2010), Özdemir ve Recepoğlu (2010), Mermi (2015), Yirci, Özdemir ve Kartal (2016), Altınkurt ve Yılmaz (2016), Yılmaz ve Akdeniz (2018) yaptıkları benzer araştırmalarda cinsiyet bakımından anlamlı bir farklılık bulamamışlardır. Yapılan benzer çalışmalara bakıldığında; Avcı (2012), Cann ve Matson (2014), Cengiz, Kayhan ve Acet (2016) öğretmenlerin mizah tarzlarına yönelik yaptıkları araştırmada, kadın öğretmenlerin mizah konusunda kendilerini daha çok geliştirdiklerini belirlemişlerdir. Çelik (2014) yaptığı araştırmada, katılımcı mizah ve kendini geliştirme alt boyutunda, Özgen (2014) ise saldırgan mizah alt boyutunda erkek öğretmenlerin puanlarının daha yüksek olduğunu ortaya koymuşlardır. Saroglou, Lacour ve Demerue (2010) yaptıkları çalışmada, erkeklerin saldırgan mizahı, kadınların ise olumlu mizahı daha fazla kullandıklarını saptamışlardır.

Araştırma bulguları evli Beden Eğitimi öğretmenlerin bekar öğretmenlere göre mizahı eğitimde gerekli görme algılarının daha yüksek olduğunu göstermektedir. Akkaya (2011) yaptığı araştırmada benzer sonuç elde ederken Özgen (2014) ve Mermi (2015) bekar öğretmenler lehine sonuç elde etmiştir. Evlilik uyumu ve mizahla ilgili yapılan çalışmalarda olumlu mizahı kullanan çiftlerin evlilik uyumlarının olumsuz mizahı kullananlara göre daha yüksek olduğu görülmektedir (Ammerman, 2002; Jacobs, 1985). Jacobs (1985), eşler arasında yakınlığı artırmak için yapılan 
mizahın yüksek düzeyde evlilik uyumuyla, saldırgan mizahın ise düşük düzeyde evlilik uyumuyla ilişkili olduğunu belirlemiştir. Buna göre evli Beden Eğitimi öğretmenlerinin birbirleriyle uyum sağlamak için kullandıkları mizah anlayışını eğitim ortamına aktarma inançlarının daha yüksek olduğu belirtilebilir. Dolayısıyla öğretmenlerin de diğer bireylerle sosyalleşme, iletişim kurma, uyum sağlama gibi davranışları mizah anlayışı oluşturmalarına katkı sağladığı sonucuna varılabilir.

Araştırmada 40-49 yaş aralığındaki Beden Eğitimi öğretmenlerinin 23-29 yaş aralığındaki öğretmenlere göre eğitimde mizah kullanımına yönelik tutumlarında sınıf düzeninin sağlanmasına etki açısından inançlarının daha fazla olduğu görülmektedir. Ortaya çıkan bu sonuç, yaşları yükseldikçe deneyim kazanan Beden Eğitimi öğretmenlerinin sınıf disiplini sağlama açısından eğitimde mizah kullanmaya daha eğilimli olduklarını göstermektedir. Yaşı daha küçük olan öğretmenlerin öğrenciler üzerinde otorite kurmak ve disiplinli öğretmen görüntüsü vermek amacıyla sınıf disiplini sağlama açısından eğitimde mizah kullanma inançlarının daha az olduğu ifade edilebilir. Nitekim bazı öğretmenlerin mizah içerikli bir dersi başarılı bulmalarına rağmen, disiplini bozma ve konudan kopma endişesinden dolayı derslerinde mizaha pek fazla yer vermedikleri görülmektedir (Yolcu, Gündoğdu ve Akar, 2018). Konuyla ilgili benzer araştırmalara bakıldığında Mermi (2015), 20-30 yaş aralı̆̆ındaki öğretmenlerin 41 yaş ve üzeri öğretmenlere göre mizah algılarının daha yüksek olduğunu belirlemiştir. Buna karşın Sepetçi (2010), Fındıklı (2013) ve Özgen (2014), öğretmenlerin mizah tarzları üzerine yaptıkları araştırmalarda tam tersi bulgular elde etmişlerdir. Sonuç olarak yaşları daha ileri olan ve yaşlarına paralel olarak mesleki deneyim kazanan öğretmenlerin eğitimde disiplin sağlama açısından otoriter, sert mizaçlı bir öğretmen davranışı sergilemekten ziyade, mizahi bir yaklaşımı tercih ettikleri görülmektedir.

Araştırmada 1-5 ve 6-10 hizmet y1lına sahip Beden Eğitimi öğretmenlerinin 1116 hizmet yılına sahip öğretmenlere göre mizahı eğitimde gerekli görme inançlarının daha fazla olduğu belirlenmiştir. Dolayısıyla hizmete yeni başlayan Beden Eğitimi öğretmenlerinin eğitimde mizahı daha fazla kullandıkları görülmektedir. Ayrıca öğretmenlerin mesleğe yeni başladıkları andan itibaren öğrencilerini tanıma, anlama ve onlarla iletişim kurma anlamında mizahı kullandıkları düşünülebilir. Konuyla ilgili benzer araştırmalara bakıldığında, Çimen (2011), 1-5 çalışma yılına sahip öğretmenlerin mizah algılarının diğerlerine göre daha yüksek olduğunu belirlerken Mermi (2015), bu araştırma bulgularının tersi sonuç elde etmiştir. Avşar (2008), Yirci ve diğerleri (2016), Altınkurt ve Yılmaz (2016) ise, hizmet yılına göre öğretmenlerin eğitimde mizah kullanımına yönelik tutumlarında anlamlı bir farklılık saptamamışlardır.

Araştırmada 1-5 hizmet yllına sahip Beden Eğitimi öğretmenlerinin 11-15 hizmet yılına sahip öğretmenlere göre dil ve öğretime etki açısından eğitimde mizahın kullanımına yönelik tutumlarının daha fazla olduğu ortaya çıkmıştır. Dolayısıyla mesleğe yeni başlayan öğretmenler eğitim programlarında mizahın yer almasını önemsemekte, mizahın öğretici yönü olduğunu ve ders anlatımına zenginlik kattığını 
düşündükleri görülmektedir. Bu bağlamda yeni mezun olan, mesleğe yeni başlayan öğretmenlerin eğitimde mizahın kullanımını daha çok önemsedikleri belirtilebilir. Ek olarak araştırma sonucundaki hizmet yıllarının ortalamalarına bakıldığında üç grupta da eğitimde mizahı gerekli görme ile dil ve öğretime etki alt boyutlarında yüksek olduğu görülmektedir. Eğitimde mizahın kullanılmasının sınıf ortamında olumlu etki oluşturduğu belirtilmektedir (Zhang ve Xu, 2011). Bu bağlamda Beden Eğitimi öğretmenlerinin eğitim ortamında mizah kullanımının öğrenme açısından öğrenciler üzerinde olumlu etki sağladığının farkında oldukları belirtilebilir.

$\mathrm{Bu}$ araştırma bir ilde görev yapan Beden Eğitimi öğretmenlerine uygulanmıştır ve öğretmenlerin mizah kullanımlarına yönelik tutumları bazı sınırlı değişkenler açısından değerlendirilmiştir. Gelecek çalışmalarda araştırmanın örneklem grubu genişletilebilir. Öğretmenlerin mizah kullanımına etki eden etmenler (psikolojik, sosyolojik vb.) daha derinlemesine araştırılabilir.

Beden eğitimi dersinde eğlence ve disiplin etkili olan iki önemli öğedir. Bu açıdan Beden Ĕ̆itimi öğretmenleri derslerinin yapısı gereği açık veya kapalı alanlarda hem öğrencileri kontrol edebilmeli hem de dersin eğlenceli ve akıcı bir şekilde işlenmesini sağlayabilmelidir. Beden Eğitimi öğretmenlerinin eğitim ortamında mizahı etkili ve dengeli bir şekilde kullanmaları dersin işleyiş̧ini kolaylaştıracak, verimini arttıracak ve dersi daha eğlenceli hale getirecektir. Bu bağlamda mesleğe yeni başlayan Beden Eğitimi öğretmenlerinin sınıf disiplinini sağlamada mizah anlayışlarını yansıtmaları öğrencilerin derse yönelik ilgilerinin artmasını kolaylaştıracaktır. Ayrıca bekar Beden Eğitimi öğretmenlerinin öğrencileriyle birlikte ya da sosyal ortamlarda daha fazla vakit geçirerek insanlarla uyum sağlama anlamında kendilerini geliştirmeleri mizah yeteneklerinin gelişimini de sağlayacaktır. Mesleki hizmet yılı fazla olan öğretmenlerde iş tükenmişliği yaşanabilir. Dolayısıyla uzun yıllar çalışan Beden Eğitimi öğretmenleri işlerini severek yaptıklarında, öğrencilerle duygusal bağ kurduklarında, mesleki kıdemlerini ve tükenmişliklerini bir yana bırakarak otorite ve espri anlayışlarını dengeli bir şekilde öğrencilere yansıttıklarında öğrencilerin de mizah yeteneklerinin gelişimini sağlamış olacaklardır.

\section{Etik Kurul Kararı}

Bu araştırma, Afyon Kocatepe Üniversitesi Sosyal ve Beşeri Bilimleri Bilimsel Araştırma ve Yayın Etiği Kurulu'nun 27.05.2020 tarih ve 04 toplantı sayılı izni ile uygun bulunmuştur.

\section{Kaynakça}

Akkaya, M. (2011). Sinıf öğretmenlerinin sınıf yönetimi becerileri ile mizah tarzları arasındaki ilişkinin incelenmesi (İstanbul ili Şişli ilçesi örneği) (Yayımlanmamış yüksek lisans tezi). Yeditepe Üniversitesi, Sosyal Bilimler Enstitüsü, İstanbul.

Alatalo, S., and Poutiainen, A. (2016). Use of humor in multicultural classroom. The Israeli Journal of Humor Research, 5(1), 65-79. Retrieved from: 
https://www.theseus.fi/bitstream/handle/10024/123975/Alatalo_Use\%20of\%20 Humour.pdf?sequence=1\&isAllowed=y

Altınkurt, Y. ve Yılmaz, K. (2016). Öğretmenlerin mizah tarzları ile örgütsel sinizm düzeyleri arasındaki ilişki. Sakarya Üniversitesi Eğitim Fakültesi Dergisi, (32), 122-143. https://dergipark.org.tr/en/download/article-file/323213 adresinden erişilmiştir.

Ammerman, M. C. (2002). Gender differences in the use of humor in intimate relationships and marital adjustment (Unpublished doctoral dissertation). Peperdine University, USA. Retrieved from https://www.proquest.com/openview/d3d24f0f794f2a187107d1df5cd6d5f4/1?p q-origsite $=$ gscholar $\& \mathrm{cbl}=18750 \&$ diss $=\mathrm{y}$

Avcı, N. (2012). Üniversite öğrencilerinin mizah tarzlarının, psikolojik belirtiler ve ölüm kaygısı ile ilişkisi (Yayımlanmamış yüksek lisans tezi). Sakarya Üniversitesi, Sosyal Bilimler Ensitüsü, Sakarya.

Avşar, V. (2008). Öğretmen adaylarının mizah tarzlarl ve cinsiyet rolleri ilişkisi (Yayımlanmamış yüksek lisans tezi). Marmara Üniversitesi, Eğitim Bilimleri Enstitüsü, İstanbul.

Balta, E. E. (2016). Eğitimde mizahın kullanımına ilişkin öğretmen tutumları. Elementary Education Online, 15(4), 1268-1279. doi: 10.17051/io.2016.64984

Berk, R. A. (2003). Professors are from Mars, students are from snickers: How to write and deliver humor in the classroom and in Professional presentations. Sterling, VA: Stylus Publishing.

Cann, A., and Matson, C. (2014). Sense of humor and social desirability: Understanding how humor styles are perceived. Personality and Individual Differences, 66, 176-180. doi: 10.1016/j.paid.2014.03.029

Cengiz, R., Kayhan, M. ve Acet, M. (2016). Beden eğitimi öğretmenlerinin mizah tarzları ile algılanan duygusal bezdirme üzerine araştırma. International Journal of Science Culture and Sport, 4(2), 2148-1148.

Chaniotakis, N. (2012). Humor im unterricht: Ansichten der lehrer. MENON, 1, 100111. Retrieved from https://www.academia.edu/6187981/Humor_im_Unterricht_Ansichten_der_Le hrer

Cohen, J. (1988). Statistical power analysis for the behavioral sciences. Hillsdale, NJ: Lawrence Erlbaum.

Çelik, B. (2014). Dokuzuncu sınıf bilgi ve iletişim teknolojisi dersinde mizah ve kavram karikatürü kullanımının öğrenci başarısı, tutumu, kaygısı ve kalıcılı̆̆a etkisi (Yayımlanmamış yüksek lisans tezi). Adnan Menderes Üniversitesi, Eğitim Bilimleri Ensitüsü, Aydın.

Çimen, B. (2011). Devlet ve özel okullarda görev yapan sını öğretmenlerinin öğretim sürecinde mizah kullanma yeterlilikleri konusundaki algılarının incelenmesi 
(Yayımlanmamış yüksek lisans tezi). Akdeniz Üniversitesi, Sosyal Bilimler Enstitüsü, Antalya.

Davis, E. M. (2015). Humor in teaching: An analysis of the literature. New York: United States Military Academy West point.

Dupré, A. (1998). Humor and the healingarts: A multi method analysis of humor use in healthcare. Mahwah, NJ: Lawrence Erlbaum Associates.

Findıklı, E. B. (2013). Okul yöneticilerinin mizah tarzları ile yaşam doyumları arasındaki ilişki (Yayımlanmamış yüksek lisans tezi). Yeditepe Üniversitesi, Sosyal Bilimler Enstitüsü, İstanbul.

Garner, R. L. (2006). Humor in pedagogy: How ha-ha can lead to aha! College Teaching, 54(1), 177-180. doi: 10.3200/CTCH.54.1.177-180

Halula, S. P. (2013). What role does humor in the higher education classroom play in student-perceived instructor effectiveness (Unpublished doctoral dissertaition). Marquette University, Milwaukee, Wisconsin. Retrieved from https://epublications.marquette.edu/dissertations_mu/252/

Harland, T. (2012). University teaching: An introductory guide. London: Routledge.

Jacobs, E. (1985). The functions humor of in marital adjustment (Doctoral dissertation). University of Microfilm International, Ann Arbor. (UMI Number. 8514188). Retrieved from https://www.proquest.com/openview/39bc730ad00bbc691e02c9eb14a1d940/1? pq-origsite $=$ gscholar $\&$ cbl $=18750 \&$ diss $=y$

Jeder, D. (2015). Implications of using humor in the classroom. Procedia-Social and Behavioral Sciences, 180(2015), 828-833. doi: 10.1016/j.sbspro.2015.02.218

Karasar, N. (2018). Bilimsel araştırma yöntemi: Kavramlar, ilkeler, teknikler. Ankara: Nobel Yayınc1lı.

Kember, D., and Kwan, K. P. (2002). Lecturers' approaches to teaching and their relationship to conceptions of good teaching. In N. Hativa and P. Goodyear (Eds.), Teacher thinking, beliefs and knowledge in higher education (pp. 219239). Dordrech, Netherlands: Springer.

Lei, S. A., Cohen, J. L., and Russler, K. M. (2010). Humor on learning in the college classroom: Evaluating benefits and drawbacks from instructors' perspectives. Journal of Instructional Psychology, 37(4), 326-331. Retrieved from: https://eric.ed.gov/?id=EJ952139

Lovorn, M., and Holaway, C. (2015). Teachers' perceptions of humour as a classroom teaching, interaction, and management tool. European Journal of Humour Research, 3(4), 24-35. doi: 10.7592/EJHR2015.3.4.lovorn

Mermi, Ö. F. (2015). Öğretmenlerin mesleki tükenmişlikleri ile mizah tarzları arasındaki ilişki (Yayımlanmamış yüksek lisans tezi). Gaziantep Üniversitesi, Eğitim Bilimleri Enstitüsü, Gaziantep. 
Mierop, J. (1999). Satisfaction (Unpublished master dissertation). California State University, UMI Dissertation Information Service.

Minchew, S. S., and Hopper, P. F. (2008). Techniques for using humor and fun in the language arts classroom. The Clearing House, 81(5), 232-236. doi: 10.3200/TCHS.81.5.232-236

Omede, J., and Daku, N. J. (2013). Teachers' perception of humor and laughter as pedagogical tools for promoting learning in Kogi State College of Education, Ankpa, Nigeria. Journal of Emerging Trends in Educational Research and Policy Studies, 4(5), 706-711.

Oral, G. (2004). Ergenlikte mizah ölçeği. Ĕ̌itim ve Bilim, 29(133), 20-27. http://egitimvebilim.ted.org.tr/index.php/EB/article/view/5058/1173 adresinden erişilmiştir.

Özdemir, S. ve Recepoğlu, E. (2010). Örgütsel sağlık ve mizah. N. Argun (Ed.), V. ulusal eğitim yönetimi kongresi bildiri kitabı içinde (ss. 219-229). Ankara: Nobel.

Özgen, G. (2014). Üsküdar bölgesinde görev yapan ögretmenlerin mizah tarzları ve dini başa çıkma tarzları arasındaki ilişki (Yayımlanmamış yüksek lisans tezi). Marmara Üniversitesi, Sosyal Bilimler Enstitüsü, İstanbul.

Pala, İ. (1995). Ansiklopedik divân şiiri sözlüğü. Ankara: Akçağ Yayınları.

Polimeni, J., and Reiss, J. P. (2006). The first joke: Exploring the evolutionary origins of humor. Evolutionary Psychology, 4, 347-366. doi: 10.1177/147470490600400129

Provine, R. (1996). Laughter. American Scientist, 84(1), 38-45. Retrieved from: https://www.jstor.org/stable/29775596?casa_token=_61osTM4YUcAAAAA\% 3ALvFgrbuBEpOdndnGBFan2nzSvPTSGgxu57V6hc3Uz_hL23ZPO0XKD20A86UQDlyStirnwhPBjcKBcuZ_o19U3C_keiUYgualmgkydRbcp_CLpFCLz2\&seq=1\#metadata_info_tab_contents

Ruch, W. (1998). The sense of humor. Berlin: Mouton de Gruyter.

Saroglou, V., Lacour C., and Demerue M. E. (2010). Bad humor bad marriage: Humor styles in divorced and married couples. Europe's Journal of Psychology, 6(3), 94-121. doi: 10.5964/ejop.v6i3.210

Sepetçi, C. (2010). Okul yöneticilerinin mizah betimlemesi (Yayımlanmamış yüksek lisans tezi). Gaziosmanpaşa Üniversitesi, Eğitim Bilimleri Enstitüsü, Tokat.

Susa, A. (2002). Humor type, orgnizational climate and outcomes: The shortest distance between an organizations environment and the bottom line is laughter (Unpublished doctoral dissertation). University of Nebraska, UMI Dissertation Information Service. Retrieved from https://digitalcommons.unl.edu/dissertations/AAI3074105/

Tabachnick B., and Fidell, L. (2013). Using multivariate statistics (6th International ed. covered). New Jersey: Sage Publications. 
Tait, G., Lampert, J., Bahr, N., and Bennett, P. (2015). Laughing with the lecturer: The use of humour in shaping university teaching. Journal of University Teaching \& Learning Practice, 12(3), 1-15. Retrieved from https://ro.uow.edu.au/cgi/viewcontent.cgi?referer=https://www.google.com/\&h ttpsredir $=1 \&$ article $=1530 \&$ context $=$ jutlp

Torok, S. E., Mcmorris, R. F., and Lin W. C. (2004). Is humor and appreciated teaching tool? College Teaching, 52(1), 14-20. doi: 10.3200/CTCH.52.1.14-20

$\mathrm{Vu}, \mathrm{P}$., and Lan, V. (2012). Techniques to bring humor and create a pleasant learning environment in adult ESL classrooms. Journal of Research and Practice for Adult Literacy, Secondary and Basic Education, 1(1), 444-447. Retrieved from https://eric.ed.gov/?id=EJ984641

Yardımcı, İ. (2010). Mizah kavramı ve sanattaki yeri. Uşak Üniversitesi Sosyal Bilimler Dergisi, 6(3/2), 1-41. https://dergipark.org.tr/tr/download/articlefile/202399 adresinden erişilmiştir.

Yılmaz, E. ve Akdeniz, Y. (2018, Ekim). Öğretmenlerin mizah tarzlarının örgütsel bağlllıklarına etkisi. 2nd International Social and Educational Sciences Symposium'da sunulan sözlü bildiri, Konya. https://www.researchgate.net/publication/329916699_Ogretmenlerin_Mizah_T arzlarinin_Orgutsel_Bagliliklarina_Etkisi adresinden erişilmiştir.

Yılmaz, M. (2010). Görsel sanatlar ĕgitiminde uygulamalar (Beşinci bask1).Ankara: Gündüz Eğitim ve Yayınevi.

Yılmaz, M. (2014). Görsel sanatlar eğitiminde mizahın yeri ve kaynakları. Akademik Bakış Uluslararası Hakemli Sosyal Bilimler Dergisi, (40), 1-22. https://dergipark.org.tr/tr/download/article-file/382691 adresinden erişilmiştir.

Yirci, R., Özdemir, T. Y. ve Kartal, S. E. (2016). Okul yöneticilerinin mizah yönelimleri. Insan ve Toplum Bilimleri Araştırmaları Dergisi, 5(8), 2479-2495. doi: 10.15869/itobiad.281489

Yolcu, O., Gündoğdu, K. ve Akar, V. R. (2018). Fen bilimleri dersinde mizah temelli geliştirilen içerik üzerine bir durum çalışması. Uluslararası Türkçe Edebiyat Kültür Eğitim Dergisi, 7(2), 1305-1332. https://dergipark.org.tr/tr/download/article-file/503715 adresinden erişilmiştir.

Yüksek Öğretim Kurulu (2007). Öğretmen yetiştirme ve eğitim fakülteleri. Ögretmenin üniversitede yetiştirilmesinin değerlendirilmesi. Bilkent, Ankara: Yüksek Öğretim Kurumu Yayını.

Zhang, W., and $\mathrm{Xu}, \mathrm{X}$. (2011). Chinese EFL learners' perceptions of humor in teaching and learning. In Z. Lu, W. Zhang, and A. Crippen (Eds.), Issues in English language teaching and learning at tertiary level (pp. 312-323). Hong Kong: Hong Kong Polytechnic University.

Ziyaeemehr, A., Kumar, V., and Abdullah, M. (2011). Use and non-use of humor in academic ESL classrooms. English Language Teaching, 4(3), 111-119. doi: 10.5539/elt.v4n3p111 


\section{Physical Education Teacher's Attitudes towards the Use of Humor in Education}

\begin{tabular}{|c|c|c|c|}
\hline $\begin{array}{l}\text { ARTICLE TYPE } \\
\text { Research Article }\end{array}$ & $\begin{array}{c}\text { Received Date } \\
06.20 .2020\end{array}$ & $\begin{array}{c}\text { Accepted Date } \\
07.26 .2021\end{array}$ & $\begin{array}{c}\text { Published Date } \\
09.03 .2021 \\
\end{array}$ \\
\hline \multicolumn{4}{|c|}{$\begin{array}{l}\text { Bijen Filiz iD } \\
\text { Afyon Kocatepe University }\end{array}$} \\
\hline & $\begin{array}{r}\text { Yasin } \\
\text { Osmaniye K }\end{array}$ & $\begin{array}{l}\text { raca } \text { iD }^{2} \\
\text { Itata University }\end{array}$ & \\
\hline
\end{tabular}

\section{Abstract}

In this research, it was aimed to determine the attitudes of Physical Education Teachers (PET) towards the use of humor in education and to examine them according to the variables of gender, marital status, age, and year of professional service. In the research, the survey model was used. The data group consisted of 140 volunteer PETs selected according to the simple random sampling method. The Attitude Scale towards the Use of Humor in Education was used. The data analysis of the research includes frequency and percentage, mean and standard deviation analysis for descriptive statistics; Variance analysis (One-way ANOVA, independent sample $t$ test) was used to compare mean scores in unrelated measurements and, the Tukey test was used to determine which groups had significant differences. As a result of the study, there was no significant difference in the attitudes of PETs towards using humor in education according to gender. It has been determined that married PETs have more attitudes towards humor deemed necessary in education, PETs who are new to the profession have more beliefs about deemed necessary in education and its effect on language and teaching towards humor, and PETs and who are older have more attitudes to use humor in the effect of maintaining classroom order. The most important result of the study is that PETs' attitudes towards the use of humor in education are at a high level in terms of the effectiveness of education.

Keywords: Physical education teacher, education, humor, humor in education, attitude.

Ethical committee approval: This research has been approved by the permission of Afyon Kocatepe University Ethics Board dated 27.05.2020-04.

${ }^{1}$ Corresponding Author: Assoc. Prof, Faculty of Sport Sciences, Department of Coaching Education, Email: bijenfiliz@gmail.com, https://orcid.org/0000-0001-5863-3861

${ }^{2}$ Assist Prof, Kadirli School of Applied Sciences, Department of Recreation Menagement, E-mail: yasinkaraca99@gmail.com, https://orcid.org/0000-0001-6024-7679 


\section{Purpose and Significance}

Humor takes place at every stage of daily life, from politics to social events, habits, and activities. Any event may be the subject of humor, provided that it is not offensive or destructive (Pala, 1995). Humor contributes to the solution of the problem in the face of any problem and the formation of a mediation environment (Mierop, 1999; Yardimc1, 2010). Humor enhances interpersonal interaction by facilitating the fusion of people (Provine, 1996). Humor is a kind of physical and psychological relaxation tool due to its contribution to reducing pain and strengthening the heart and muscles (Dupré, 1998). A person who laughs as a result of humor feels happy and relaxed. Humor helps to calm the nerves and calm the person by reducing stress. Many disciplines see and use humor as a viable pedagogical approach. Especially in the educational environment, the use of humor plays an important role in predicting student-teacher relationships and students' satisfaction level and establishing a strong relationship.

The fact that teachers have detailed information about the use of humor in their relations with students while conducting educational activities helps to create a more complete and detailed picture of what the educational activity takes place in the classroom. This also means that the teaching profession is performed in accordance with ethical standards (Jeder, 2015). The sense of humor is seen as one of the basic qualities that teachers should have. Teachers often create humor using jokes, funny analogies, hints, irony, and role-play to relax and lighten the environment in lessons. Using the humor of the teacher helps to create skills such as trust, relaxation, relaxation, positive view of life and well-being on the student. Teachers should discover new ways to use humor in lessons, understand jokes, anticipate the ridiculous aspects of events, and avoid words and behaviors that can offend students (Y1lmaz, 2010). When teachers use humor in the right place, they manage to draw the attention of the student to the subject they want to teach. The student can distinguish the inferences, have positive experiences and increase motivation to the lesson thanks to the humor used correctly. This situation increases the student's academic success as well as learning ability (Jeder, 2015).

It is seen that the personal preferences of teachers mostly determine the use of humor in education. It is thought that it is more beneficial for Physical Education Teachers (PET) to use humor in their classes in order to realize more effective learning in educational environments. Higher Education Institution (Yüksek Öğretim KuruluYOK), the criteria for teaching profession, stated that a teacher who has the necessary conditions to give a Physical Education course should have the ability to use humor, play and creative drama together (YOK, 2007). Therefore, it is useful to investigate the attitudes of the PETs towards the use of humor in education in terms of making the teaching methods used by the teacher more effective, motivating the students to the lesson, increasing their love and interest in the lesson. Indeed, making the lesson fun is one of the most important sources of motivation. An entertaining lesson creates a motivating effect at every stage of education (Y1lmaz, 2010). In addition, teachers who perform their profession in the best way seek ways to be successful. It is thought 
that it is important and worth researching for teachers to use humor in their lessons in order to be more effective and efficient. In this research, it was aimed to determine the attitudes of PETs towards the use of humor in education and to examine them according to the variables of gender, marital status, age, and year of professional service.

\section{Method}

In the research, the survey model was used. In this research, The Attitude Scale towards the Use of Humor in Education was used. The scale was developed by Balta (2016). The scale was applied to a total of 313 PETs aged between 23-48. The scale has a five-point Likert type structure, consists of 17 items and three sub-dimensions $(\alpha=.92)$. The first sub-dimension was defined as the necessary vision in education $(\alpha$ $=.85)$, the second sub-dimension was the effect on language and teaching $(\alpha=.88)$, and the third sub-dimension was the effect on classroom order $(\alpha=.75)$. The items examples can be given for the first sub-dimension, "Humor provides a different view of events.", for the second sub-dimension, "There is a teaching aspect of humor.", for the third sub-dimension, "Humor disrupts the order established in the classroom." The Cronbach Alpha values obtained from this study were found to be .92 for three subdimensions, the necessary vision in education .85 , the effect on language and teaching .88 , the effect on classroom order .75 . The data analysis of the research includes frequency and percentage, mean and standard deviation analysis for descriptive statistics; Variance analysis (One-way ANOVA, independent sample t-test) was used to compare mean scores in unrelated measurements and, the Tukey test was used to determine which groups had significant differences.

The data group consisted of 140 volunteer PETs working in central of the Ministry of National of Afyon and selected according to the simple random sampling method. Before to the research, permission was obtained from the Afyon Kocatepe University (15.06.2020- E. 17011). PETs working in Afyon province were contacted through Whatsup groups they participated in and the data were collected on an electronic scale via a Google questionnaire. The electronic scale included the preliminary information form for approval, the purpose of the study, the time distribution, the inclusion criteria, and the participants' right to withdraw. The teachers who accepted the preliminary information filled the scale.

\section{Results}

A significant difference was not found in the attitudes of PETs towards using humor in education according to gender. A significant difference was found in the deemed necessary in education sub-dimension of PETs' attitudes towards the use of humor in education according to marital status. There was a difference in favor of married in the deemed necessary in education sub-dimension $(t=2.38 ; p<.05)$. There was a significant difference between the mean scores of PETs' attitudes towards the use of humor in education in the effect on the provision of classroom order subdimension $\left(F_{(2,137)}=3.90, p<.05\right)$ in favor of $40-49$ years according to age. There was a significant difference between the mean scores of PETs' attitudes towards the use 
of humor in education in the deemed necessary in education sub-dimension $\left(F_{(3,136)}=\right.$ $3.85, p<.05)$ in favor of $1-5$ and $6-10$ working years according to the year of professional service. There was a significant difference between the mean scores of PETs' attitudes towards the use of humor in education in the effect of language and teaching sub-dimension $\left(F_{(3,136)}=3.05, p<.05\right)$ in favor of $1-5$ working years according to the year of professional service.

\section{Discussion and Conclusions}

In this research, it was aimed to determine the attitudes of PETs towards the use of humor in education and to examine them according to the variables of gender, marital status, age, and year of professional service. Humor is an effective tool in the educational setting. Therefore, teachers' attitudes and readiness towards humor in education are important (Oral, 2004). In this context, in terms of the effectiveness of education, the high level of PETs' attitudes towards the use of humor in education is an important result.

As a result of the research, no difference was found in the perceptions of PETs using humor in education according to gender. In addition, it has been determined that PETs who have fewer years of service and are married use more humor in education. It is determined that PETs who are older than age prefer to use humor more in class discipline. The most important result of the study is that PETs' attitudes towards the use of humor in education are quite high in terms of the effectiveness of education. In this context, it can be stated that PETs are aware that the use of humor in the educational environment has a positive effect on students in terms of learning.

This research was applied to PETs working in a province and their humor usage was evaluated in terms of some limited variables. In future studies, the sample group of the research can be expanded. Factors affecting teachers' use of humor (psychological, sociological, etc.) can be further investigated. In addition, the reasons for the differences in the use of PETs with humor can be examined.

Entertainment and discipline are two important factors in a Physical Education lesson. In this respect, PETs should be able to control students in open or closed areas as well as to ensure that the lesson is carried out in a fun and fluent way. Using the humor of PETs in the educational environment will facilitate the operation of the course, increase its efficiency and make the lesson more enjoyable. In this context, the fact that older PETs reflect their sense of humor besides the authoritarian approach in their lessons will make it easier for students to increase their interest in the lesson. In addition, single PETs can improve their humor skills by spending more time in social settings. Job burnout may occur in teachers who have more professional service years. Therefore, when PETs, who have been working for many years, love their jobs, have an emotional bond with students, and reflect their understanding of authority and humor to students, they will provide the development of students' humor skills.

\section{Ethical Committee Approval}

This research has been approved by the permission of Afyon Kocatepe University Ethics Board dated 27.05.2020-04. 